Provided for non-commercial research and education use. Not for reproduction, distribution or commercial use.

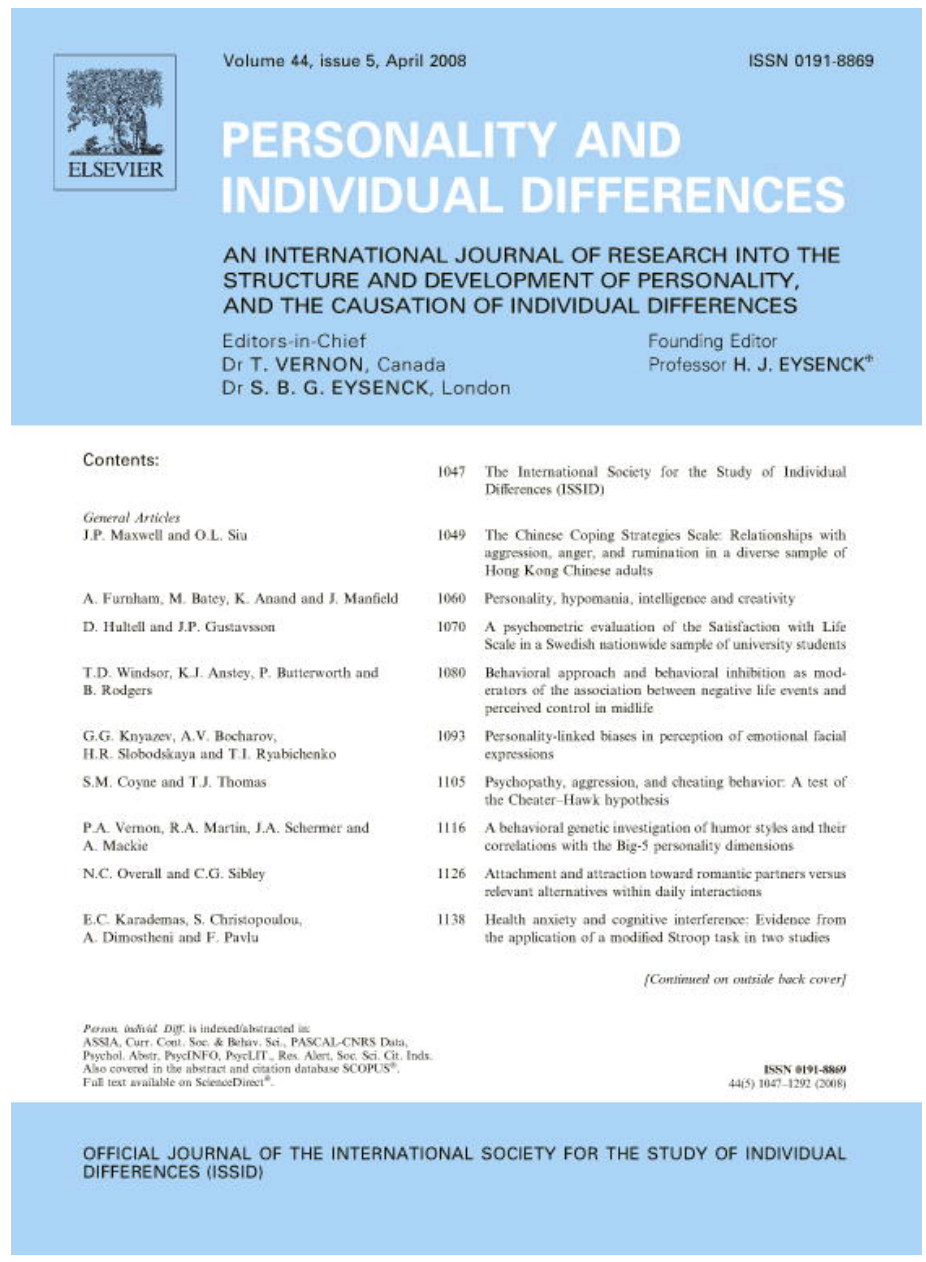

This article was published in an Elsevier journal. The attached copy

is furnished to the author for non-commercial research and education use, including for instruction at the author's institution, sharing with colleagues and providing to institution administration.

Other uses, including reproduction and distribution, or selling or licensing copies, or posting to personal, institutional or third party websites are prohibited.

In most cases authors are permitted to post their version of the article (e.g. in Word or Tex form) to their personal website or institutional repository. Authors requiring further information regarding Elsevier's archiving and manuscript policies are encouraged to visit:

http://www.elsevier.com/copyright 


\title{
Mental toughness, optimism, pessimism, and coping among athletes
}

\author{
Adam R. Nicholls ${ }^{\mathrm{a}, *}$, Remco C.J. Polman ${ }^{\mathrm{b}}$, \\ Andrew R. Levy ${ }^{c}$, Susan H. Backhouse ${ }^{\mathrm{d}}$ \\ ${ }^{a}$ Department of Psychology, The University of Hull, North Humberside HU6 7RX, UK \\ ${ }^{\mathrm{b}}$ Department of Sport, Health and Exercise Science, The University of Hull, North Humberside HU6 7RX, UK \\ ${ }^{\mathrm{c}}$ Centre for Sport and Exercise Science, University of Leeds LS2 9JT, UK \\ ${ }^{\mathrm{d}}$ Carnegie Research Institute, Leeds Metropolitan University, Leeds LS6 3QS, UK
}

Received 1 August 2007; received in revised form 8 November 2007; accepted 14 November 2007

Available online 21 December 2007

\begin{abstract}
The concept of mental toughness is widely used, but empirical evidence is required to fully understand this construct and its related variables. The purpose of this paper was to explore the relationship between: (a) mental toughness and coping, (b) mental toughness and optimism, and (c) coping and optimism. Participants were 677 athletes (male 454; female 223) aged between 15 and 58 years (M age $=22.66$ years, $\mathrm{SD}=7.20$ ). Mental toughness correlated significantly with 8 of the 10 coping subscales and optimism. In particular, higher levels of mental toughness were associated with more problem or approach coping strategies (mental imagery, effort expenditure, thought control, and logical analysis) but less use of avoidance coping strategies (distancing, mental distraction, and resignation). Eight coping subscales were significantly correlated with optimism and pessimism. In conclusion, the relationships observed in this study emphasize the need for the inclusion of coping and optimism training in mental toughness interventions. (c) 2007 Elsevier Ltd. All rights reserved.
\end{abstract}

Keywords: Mental toughness; Coping; Optimism; Pessimism

\footnotetext{
${ }^{*}$ Corresponding author. Tel.: +4401482 466052.

E-mail address: A.Nicholls@hull.ac.uk (A.R. Nicholls).
} 


\section{Introduction}

Mental toughness has recently been suggested to be an important characteristic for athletic success (Golby \& Sheard, 2004; Loehr, 1986), and yet it remains one of the least understood terms in sport psychology (Jones, Hanton, \& Connaughton, 2002). Definitions of this construct not only vary widely among coaches, sport commentators, fans, and athletes, but also among researchers. For instance, Clough, Earle, and Sewell (2002) reported that mentally tough people have "a high sense of self-belief and an unshakable faith that they control their own destiny, these individuals can remain relatively unaffected by competition and adversity" (p. 38). Conversely, Jones et al. (2002) suggested that mental toughness represents the ability of a person to cope with the demands of training and competition, increased determination, focus, confidence, and maintaining control under pressure.

To date, most researchers have relied on qualitative research paradigms to examine mental toughness. For example, mental toughness characteristics have been investigated in athletes from a variety of sports (e.g., Fourie \& Potgieter, 2001; Jones, Hanton, \& Connaughton, 2007; Jones et al., 2002) and specific sports like cricket (e.g., Bull, Shambrook, James, \& Brooks, 2005), and soccer (e.g., Thellwell, Weston, \& Greenlees, 2005). The mental toughness studies involving the cricketers and soccer players produced similar findings to those by Fourie and Potgieter, alongside Jones et al. (2002) with a strong emphasis placed on coping effectiveness (Thellwell et al., 2005) and tough thinking (Bull et al., 2005).

Given the adaptive applied implications of being mentally tough it is essential that researchers pursue sound psychometric measurement of this construct. To date, two measures have been postulated to examine mental toughness. First, Loehr (1986) developed the sport specific psychological performance inventory (PPI), based on interviews with a large number of athletes. However, the psychometric properties of the PPI have recently been criticized (Middleton et al., 2004). Secondly, grounded in Kobasa, 1979 concept of hardiness and their applied work with rugby league players, Clough et al. (2002) proposed the 4Cs model of mental toughness and developed the Mental Toughness Questionnaire 48 (MTQ48) to assess their proposed characteristics of mental toughness. The MTQ48 assesses an individual's total mental toughness and the four proposed sub-components: (a) control (emotional and life), a tendency to feel and act as if one is influential, (b) commitment, a tendency to involve oneself in rather than experience alienation from an encounter, (c) challenge, belief that life is changeable and to view this as an opportunity rather than a threat, and (d) confidence (interpersonal and in abilities), a high sense of self-belief and unshakable faith concerning one's ability to achieve success. Adequate reliability, face, construct, and criterion validity has been reported for the MTQ48 (Clough et al., 2002). For example, Crust and Clough (2005) found that individuals who scored higher on total mental toughness and on the factors of control and confidence were significantly more likely to tolerate a physical endurance task for longer than those individuals who scored lower on these factors. Other research using the MTQ48 found higher levels of mental toughness were associated with more positive threat appraisals, enhanced ability to cope with pain, and a greater attendance to clinic-based physical therapy among athletes undertaking a sport injury rehabilitation program (Levy, Polman, Clough, Marchant, \& Earle, 2006).

There are some similarities in terms of the characteristics identified which underlie mental toughness between the work of Clough and colleagues (e.g., Clough et al., 2002; Crust \& Clough, 
2005) and Jones and colleagues (Jones et al., 2002, 2007). In particular, control and confidence are perceived to be important by both teams of researchers; however, Jones et al. (2002), Jones et al. (2007) suggest that coping is also a key construct of mental toughness.

Coping refers to conscious cognitive and behavioral efforts to manage a situation that has been appraised as stressful (Lazarus, 1999; Lazarus \& Folkman, 1984). Lazarus and Folkman (1984) suggested that coping strategies either change or eliminate the stressor (problem-focused coping e.g., planning), or manage the emotional responses (emotion-focused coping e.g., deep breathing) caused by the stressor.

Based on this widely accepted conceptualization of coping in sport (Nicholls \& Polman, 2007), we believe that Jones et al. (2002), Jones et al. (2007) refer to mentally tough athletes as being able to cope effectively (Bull et al., 2005; Jones et al., 2002, 2007; Thellwell et al., 2005). However, these studies do not state whether mentally tough athletes differ in the actual coping strategies employed, in comparison to athletes that are not mentally tough. Khoshaba and Maddi (1999) have suggested that hardy people are more likely to show problem or approach based coping behavior when faced with a stressful situation. However, little is known about the specific coping strategies that mentally tough athletes may, or may not use in comparison to less mentally tough athletes. Or, as Nicholls and Polman (2007) have stated, "the relationship between coping and mental toughness appears to be an obvious one, but has not been investigated to date" (p. 18). Secondly, although it is purported by Jones and colleagues that mental toughness is relatively stable and enduring, one of its key components is not. Previous research with elite athletes provides support for Lazarus (1999), that coping changes over time (e.g., Nicholls, Holt, Polman, \& Bloomfield, 2006; Nicholls, Holt, Polman, \& James, 2005; Nicholls \& Polman, in press). Therefore, it would be premature to consider coping behavior as an essential component of mental toughness without empirical evidence.

Another psychological construct that appears to be related to both mental toughness and coping is optimism. In a qualitative study, Gould, Dieffenbach, and Moffett (2002) reported that Olympic champions report high levels of mental toughness, coping effectiveness, and optimism. Optimism, in this respect, has been defined as "a major determinant of the disjunction between two classes of behavior: (a) continued striving versus (b) giving up and turning away" (Scheier \& Carver, 1985, p. 227). Researchers became interested in studying optimism, because more optimistic individuals exhibit increased effort to achieve goals. Alternatively, less optimistic individuals are more likely to withdraw or disengage attempts at achieving a goal (e.g., Carver, Blaney, \& Scheier, 1979; Gaudreau \& Blondin, 2004; Solberg Nes, Segerstrom, \& Sephton, 2005). In addition, optimism seems to be a predictor of sport performance. In a study by Norlander and Archer (2002) it was found that optimism was the best predictor of performance in elite male and female cross country skiers and ski-marksman (16-20 years) and swimmers (16-19 years). Finally, optimism appears to be associated with differences in coping behavior. In a recent meta-analysis it was found that more optimistic individuals use more approach coping strategies and less avoidance strategies (Solberg Nes \& Segerstrom, 2006). To date, however, we are not aware of any studies that have quantitatively investigated the optimism and mental toughness relationship.

In summary, mental toughness is an appealing psychological construct to both coaches and sport psychologists. Empirical information is required to understand more about the relationship between mental toughness and the psychological constructs that are reported to determine it. As such, the purpose of this study was to explore the relationship between (a) mental toughness and 
coping, (b) mental toughness and optimism and pessimism, and (c) coping and optimism and pessimism.

\section{Method}

\subsection{Participants}

Participants were 677 athletes (male 454; female 223) aged between 15 and 58 years (M age $=22.66$ years, $\mathrm{SD}=7.20)$. The sample consisted of sports performers competing at international (60), national (99), county (198), club/university (289), and beginner (31) levels. Participants completed an informed consent form prior to study participation.

\subsection{Questionnaires}

Coping was assessed using the coping inventory for competitive sport (CICS; Gaudreau \& Blondin, 2002). The CICS examines 10 coping subscales that are categorized in three second-order dimensions (1) task-orientated coping (thought control, mental imagery, relaxation, effort expenditure, logical analysis, and seeking support), (2) distraction-orientated coping (distancing and mental distraction), and (3) disengagement-orientated coping (disengagement/resignation and venting of unpleasant emotions). The CICS has nine four-item subscales and one three item subscale, with all items being rated on a 5-point Likert-type scale anchored at $1=$ does not correspond at all to $5=$ corresponds very strongly. Adequate reliability has been demonstrated for the CICS, Cronbach's index of internal consistency ranging between 0.67 and 0.87 (Gaudreau \& Blondin, 2002). The alphas for the current study were adequate and ranged between 0.49 and 0.82 for the 10 factors and between .75 and .82 for the three higher order dimensions. In addition, support has been provided for the factorial validity for the 10-factor model as well as the 3 higher order dimensions (Gaudreau \& Blondin, 2002; Gaudreau, El Ali, \& Marivain, 2005).

The present study used the 48-item Mental Toughness Questionnaire (MTQ48; Clough et al., 2002). The MTQ48 assesses total mental toughness (MT) and six subcomponents: challenge, commitment, interpersonal confidence, confidence in own abilities, emotional control, and life control. The items on the MTQ48 rated on a 5-point Likert-type scale anchored at $1=$ Strongly disagree to $5=$ Strongly agree. The MTQ48 in the present study had an overall Cronbach's Alpha value of 0.87 with all individual scales scoring between 0.58 and 0.71 . In testing of construct validity, the MTQ48 has been correlated significantly with: self-image (.42); life satisfaction (.56); self-efficacy (.68); and trait anxiety (.57); as well as providing a significant correlation with personal endurance (Crust \& Clough, 2005).

The Life Orientation Test (LOT; Scheier \& Carver, 1985) was used to assess dispositional optimism and pessimism. The LOT consists of four positively worded items measuring optimism and four negatively worded items measuring pessimism and four fillers. The items on the LOT are rated on a 4-point Likert-type scale anchored at $1=$ Agree a little to $4=$ Totally agree. Initially, the LOT has been treated as a unidimensional measure of dispositional optimism (Scheier \& Carver, 1985). However, recent studies have found that the LOT has bi-dimensional structure consisting of an optimism and pessimism subscale (Chang, D’Zurilla, \& Maydeu-Olivares, 1994; Chang, 
Maydeu-Olivares, \& D'Zurilla, 1997). To support the adoption of the bi-dimensional model we carried out a principal component factor analysis using a varimax rotation and eigenvalues $>1$ on our data set. This resulted in a two factor solution explaining $58.2 \%$ of the variance with the positively worded items loading on factor one (factor loadings between .77 and .81) and the negatively worded items loading on factor two (factor loadings between .60 and .79). Bartlett's test of sphericity was significant $(P<0.001)$ and the Kaiser-Meyer-Olkin was good (.80). Adequate validity and reliability of the LOT has been provided previously (Scheier \& Carver, 1985). The Cronbach alphas in the present study for the optimism scale was .68 and for the pessimism scale .81 .

\subsection{Procedure}

Letters were sent to athletes and coaches of sports teams within the United Kingdom and Iceland detailing the nature of the study and participant requirements. If the coaches granted permission for the data collection, an information letter and consent forms were distributed. Assent and consent forms for parents/guardians were also distributed for participants who were under 16 years old. Questionnaires were administered in the same order by a team of research assistants who were trained in quantitative techniques. The research assistants answered any questions regarding the three questionnaires. Although the testing conditions differed for participants, completion of questionnaires was always conducted in a quiet and safe environment. Unlike the other two constructs that were investigated in this study (mental toughness and optimism) coping was not measured as being a stable personality characteristic, so instructions regarding the completion of the CICS (Gaudreau \& Blondin, 2002) were slightly different.

\subsection{Data analyses}

Means, standard deviations, and internal consistency were calculated prior to statistical analysis. Pearson product moment correlations between all the coping subscales, the subscales of the MTQ48 and optimism and pessimism were also calculated. Finally, linear regression analysis was conducted to assess the relationship between coping behavior and mental toughness and optimism/pessimism. In particular, each subscale of the CICS acted as dependent variables and optimism, pessimism and the six subscales of the MTQ48 as the independent variables.

\section{Results}

Table 1 provides the means and standard deviations for the LOT, MTQ48, and CICS, respectively. Tables 2 and 3 provide information with regard to the correlation analysis whereas Table 2 provides the results of the regression analysis. Eight of 10 coping scales were significantly correlated with mental toughness. That is, higher levels of mental toughness were associated with more problem or approach coping strategies (mental imagery, effort expenditure, thought control, and logical analysis) but less use of avoidance coping strategies (distancing, mental distraction, and resignation; see Table 2).

Positive, moderate to high correlations were found between total mental toughness and the six subscales of mental toughness (e.g., challenge, commitment, emotional control, life control, ability 
Table 1

Mean and standard deviations for optimism/pessimism, mental toughness, and coping behavior among athletes

\begin{tabular}{llll}
\hline Dependent variables & $(N=677)$ & Minimum & Maximum \\
\hline Optimism & $15.82(2.03)$ & 7 & 20 \\
Pessimism & $6.58(2.64)$ & 4 & 16 \\
Mental toughness total & $173.1(17.9)$ & 99 & 214 \\
Challenge & $3.76(0.43)$ & 2.25 & 4.75 \\
Commitment & $3.72(0.50)$ & 2.00 & 4.91 \\
Emotional control & $3.22(0.52)$ & 1.71 & 4.86 \\
Life control & $3.63(0.51)$ & 1.86 & 5.00 \\
Ability confidence & $3.57(0.51)$ & 1.33 & 5.00 \\
Interpersonal confidence & $3.67(0.67)$ & 1.33 & 5.00 \\
Mental imagery & $3.35(0.76)$ & 1.00 & 5.00 \\
Effort expenditure & $3.99(0.67)$ & 1.00 & 5.00 \\
Thought control & $3.63(0.63)$ & 1.25 & 5.00 \\
Seeking support & $2.39(0.89)$ & 1.00 & 4.75 \\
Relaxation & $2.73(0.78)$ & 1.00 & 4.75 \\
Logical analysis & $3.25(0.75)$ & 1.00 & 5.00 \\
Distancing & $2.07(0.73)$ & 1.00 & 4.50 \\
Mental distraction & $1.85(0.76)$ & 1.00 & 4.50 \\
Venting emotions & $2.86(1.03)$ & 1.00 & 5.00 \\
Resignation & $1.65(0.69)$ & 1.00 & 4.50 \\
\hline
\end{tabular}

Table 2

Results of the pearson product moment correlation analysis between the coping strategies and the personality variables optimism/pessimism and mental toughness

\begin{tabular}{|c|c|c|c|c|c|c|c|c|c|}
\hline & Optimism & Pessimism & $\begin{array}{l}\text { Mental } \\
\text { toughness }\end{array}$ & Challenge & $\begin{array}{l}\text { Commit- } \\
\text { ment }\end{array}$ & $\begin{array}{l}\text { Emotional } \\
\text { control }\end{array}$ & $\begin{array}{l}\text { Life } \\
\text { control }\end{array}$ & $\begin{array}{l}\text { Ability } \\
\text { confidence }\end{array}$ & $\begin{array}{l}\text { Interpersonal } \\
\text { confidence }\end{array}$ \\
\hline $\begin{array}{l}\text { Mental } \\
\text { imagery }\end{array}$ & $.29^{* *}$ & $-.10^{* *}$ & $.17^{* *}$ & $16^{* *}$ & $.17^{* *}$ & .01 & $.10^{* *}$ & $.15^{* *}$ & $.09^{*}$ \\
\hline $\begin{array}{l}\text { Effort } \\
\quad \text { expenditure }\end{array}$ & $.25^{* *}$ & $-.24^{* *}$ & $.26^{* *}$ & $.21^{* *}$ & $.32^{* *}$ & $.08^{*}$ & $.19^{* *}$ & $.18^{* *}$ & $.11^{* *}$ \\
\hline $\begin{array}{l}\text { Thought } \\
\text { control }\end{array}$ & $.27^{* *}$ & $-.14^{* *}$ & $.27^{* *}$ & $.22^{* *}$ & $.23^{* *}$ & .06 & $.21^{* *}$ & .25 & $.17^{* *}$ \\
\hline $\begin{array}{l}\text { Seeking } \\
\text { support }\end{array}$ & $.13^{* *}$ & .06 & .02 & -.02 & .01 & -.06 & .00 & .07 & .06 \\
\hline Relaxation & $.09^{*}$ & -.02 & $.10^{* *}$ & .07 & $.09^{*}$ & .05 & $.08^{*}$ & $.12^{* *}$ & .02 \\
\hline $\begin{array}{l}\text { Logical } \\
\text { analysis }\end{array}$ & $.28^{* *}$ & $.11^{* *}$ & $.30^{* *}$ & $.25^{* *}$ & $.27^{* *}$ & $.09^{*}$ & $.22^{* *}$ & $.22^{* *}$ & $.21^{* *}$ \\
\hline Distancing & -.05 & $.18^{* *}$ & $-.09^{*}$ & -.06 & $-.12^{* *}$ & -.06 & $-.09^{*}$ & -.07 & .03 \\
\hline $\begin{array}{l}\text { Mental } \\
\text { distraction }\end{array}$ & $-.11^{*}$ & $.30^{* *}$ & $-.19^{* *}$ & $-.15^{* *}$ & $-.15^{* *}$ & $-.15^{* *}$ & $-.14^{* *}$ & $-.12^{* *}$ & $-.12^{* *}$ \\
\hline $\begin{array}{l}\text { Venting } \\
\text { emotions }\end{array}$ & .05 & $.13^{* *}$ & -.01 & .03 & .04 & $-.15^{* *}$ & .00 & $-.09^{*}$ & $-.12^{* *}$ \\
\hline Resignation & $-.23^{* *}$ & $.33^{* *}$ & $-.28^{* *}$ & $-.23^{* *}$ & $-.23^{* *}$ & $-.11^{* *}$ & $-.24^{* *}$ & $-.26^{* *}$ & $-.14^{* *}$ \\
\hline
\end{tabular}

\footnotetext{
${ }^{*} P<0.05$.

** $P<0.01$.
} 
Table 3

Results of the pearson product moment correlation analysis between the personality variables optimism/pessimism and mental toughness

\begin{tabular}{lll}
\hline & Optimism & Pessimism \\
\hline Mental toughness & $.56^{* *}$ & $-.46^{* *}$ \\
Challenge & $.48^{* *}$ & $-.31^{* *}$ \\
Commitment & $.52^{* *}$ & $-.33^{* *}$ \\
Emotional control & $.08^{*}$ & $-.24^{* *}$ \\
Life control & $.48^{* *}$ & $-.43^{* *}$ \\
Ability confidence & $.38^{* *}$ & $-.49^{* *}$ \\
Interpersonal confidence & $.42^{* *}$ & $-.16^{* *}$ \\
\hline
\end{tabular}

${ }^{*} P<0.05$.

** $P<0.01$.

confidence, and interpersonal confidence) and optimism. Negative correlations were found for mental toughness and pessimism (see Table 3).

Eight of the 10 coping subscales (e.g., mental imagery, effort expenditure, thought control, seeking support, relaxation, logical analysis, mental distraction, and resignation) were significantly correlated with optimism and pessimism, respectively. Higher levels of optimism were associated with more mental imagery, effort expenditure, thought control, and logical analysis, whereas pessimism was associated with significantly less use of these coping strategies. Resignation was positively correlated with pessimism, but negatively correlated with optimism.

\section{Discussion}

The first purpose of this paper was to explore the relationship between mental toughness and coping among athletes. The current study found low to moderate, but highly significant correlations for total mental toughness and 8 of the 10 coping scales of the CICS (Gaudreau \& Blondin, 2002). The directions of these correlations are in agreement with the description of mental toughness forwarded by Clough et al. (2002) and findings by Khoshaba and Maddi (1999).

Correlation results for the subscales of the MTQ48 and the CICS factors were similar except for the emotional control scale. The latter showed significant negative correlations with mental distraction, venting emotions, and resignation but not with the approach coping strategies. Seeking support and to a lesser extent venting emotions and relaxation appeared to be less associated with mental toughness. The notion that seeking support is not compatible with mental toughness corroborates the definitions provided in the literature and probably the common perception that a mentally tough athlete is able to bounce back or resolve issues without recourse to others. Also, overt venting of emotions can be perceived as a sign of mental weakness rather than strength. Finally, Dienstbier (1989) has suggested that relaxation is not compatible with development of mental toughness. He suggested that using relaxation techniques could result in removing the very situation that lead to the athlete becoming more mentally tough (see Table 4).

Previous research has emphasized the importance of coping as a key factor relating to mental toughness (e.g., Bull et al., 2005; Jones et al., 2002, 2007; Thellwell et al., 2005) but these studies failed to identify which coping strategies mentally tough athletes use. Our findings suggest that 
Table 4

Results of the linear regression analysis

\begin{tabular}{|c|c|c|c|}
\hline Dependent variable & $R^{2}$ & ANOVA & Variables loading significantly and beta value \\
\hline Mental imagery & .10 & $9.19 ; P<0.001$ & Optimism $(\beta=.11)$; life control $(\beta=-20)$; confidence ability $(\beta=.18)$ \\
\hline Effort expenditure & .14 & $13.14 ; P<0.001$ & Optimism $(\beta=.04)$; pessimism $(\beta=-.04)$; commitment $(\beta=.39)$ \\
\hline Thought control & .10 & $9.58 ; P<0.001$ & Optimism $(\beta=.05)$; confidence ability $(\beta=.20)$ \\
\hline Seeking support & .06 & $4.81 ; P<0.001$ & $\begin{array}{l}\text { Optimism }(\beta=.09) \text {; pessimism }(\beta=.04) \text {; challenge }(\beta=-.21) \text {; } \\
\text { confidence ability }(\beta=.32)\end{array}$ \\
\hline Relaxation & .02 & $2.03 ; P=0.04$ & Confidence ability $(\beta=.22)$ \\
\hline Logical analysis & .11 & $10.6 ; P<0.001$ & Optimism $(\beta=.06) ;$ commitment $(\beta=.17)$ \\
\hline Distancing & .04 & $3.82 ; P<0.001$ & $\begin{array}{l}\text { Pessimism }(\beta=.05) \text {; Commitment }(\beta=-.18) \text {; Interpersonal } \\
\text { confidence }(\beta=.10)\end{array}$ \\
\hline Mental distraction & .11 & $10.71 ; P<0.001$ & $\begin{array}{l}\text { Pessimism }(\beta=.09) \text {; emotional control }(\beta=-.16) \text {; confidence ability } \\
(\beta=.21) \text {; interpersonal confidence }(\beta=-.12)\end{array}$ \\
\hline Venting emotions & .06 & $5.32 ; P<0.001$ & $\begin{array}{l}\text { Pessimism }(\beta=.05) \text {; emotional control }(\beta=-.23) \text {; confidence ability } \\
(\beta=-.23) \text {; interpersonal confidence }(\beta=.16)\end{array}$ \\
\hline Resignation & .14 & $12.96 ; P<0.001$ & Pessimism $(\beta=.06)$ \\
\hline
\end{tabular}

athletes who are mentally tough use more approach coping strategies and less avoidance strategies. Finally, the different underlying characteristics of mental toughness proposed by Clough et al. (2002) showed subtle differences with coping. For example, lower levels of emotional control were associated with more venting of emotions whereas higher levels of challenge, commitment and ability confidence were associated with more use of mental imagery.

The second purpose of this research was to examine the relationship between mental toughness and optimism and pessimism. Positive, moderate to high correlations were found between total mental toughness and the six subscales and optimism whereas negative correlations were found for mental toughness and pessimism. These results provide support for Gould, Dieffenbach, and Moffett, (2002) qualitative study, that there is a relationship between optimism and mental toughness. This finding has important implications for mental toughness training interventions, because previous research indicates that optimism can be learned (e.g., Seligman, 1990). Teaching athletes optimism skills could therefore enhance mental toughness. However, further research is required to empirically examine this theoretical proposition.

The third purpose of this study was to explore the relationship between coping and optimism and pessimism. We found evidence to suggest that coping is highly related to optimism and pessimism. Our findings, with an athletic population, support previous research that less optimistic individuals are more likely to withdraw or disengage (e.g., Carver et al., 1979; Solberg Nes, Segerstrom, and Sephton, 2005) and that more optimistic individuals use more approach coping strategies, but less avoidance strategies (Solberg Nes \& Segerstrom, 2006). Seligman (1998) also suggested that optimism results in higher levels of achievement. The strong association between mental toughness and optimism would suggest that higher levels of mental toughness could potentially result in higher levels of achievement. Venne, Laguna, Walk, and Ravizza (2006) discussed different pathways to increase optimism. They identified successful achievement of mastery experiences, lower levels of anxiety and depression and explanatory style as possible mechanisms. Similar routes could result in increased mental toughness; however, this would need further investigation. 
When analyzing the relationship between coping behavior, mental toughness, and optimism and pessimism, we found that optimism was a good predictor of task oriented coping whereas pessimism was a good predictor of distraction and disengagement oriented coping. With regard to the MTQ48 factors, the different subscales predicted the use of different coping strategies. For example, confidence in one's ability was positively associated with task oriented coping and negatively associated with distraction and disengagement coping. People who scored high on commitment used more increased effort expenditure and logical analysis coping strategies, but used less distancing to cope. Finally, higher levels of emotional control resulted in less venting of emotions or mental distraction whereas higher levels of interpersonal confidence resulted in higher levels of venting emotions and distancing but less mental distraction.

Although this study was not designed to examine the underlying causes of this observed relationship, emerging research suggests genetic variables, namely the 5-HTT gene (polymorphism of the serotonin transporter) are linked to mental toughness within everyday life settings (e.g., Caspi et al., 2003) and sport (e.g., Golby \& Sheard, 2006). Additionally, the cognitive-affective processing system (CAPS; Mischel \& Shoda, 1995) has been applied to sport by Smith (2006). He suggested that mentally tough athletes believe they are able to cope successfully with pressure situations and have positive outcome expectancies (linking mental toughness to coping and optimism). Genetic research and studies exploring CAPS have the potential to shed more light on mental toughness.

A limitation of this research is that the constructs were measured via self-reported questionnaires and that we employed a cross-sectional design, meaning that causality cannot be established from the relationships found. Experimental research is required to establish directionality or causation. For example, if mental toughness can be enhanced through psychological skill training (e.g., Sheard \& Golby, 2006) will this alter coping behavior or vice versa? Coping (e.g., Nicholls \& Polman, in press; Nicholls et al., 2005, 2006) and coping effectiveness (e.g., Nicholls, 2007) have been found to change over time with athletic populations, so it would be interesting to examine whether coping and coping effectiveness fluctuations influence mental toughness via longitudinal research designs.

In summary, previous qualitative research has suggested that both coping and optimism were key psychological characteristics among mentally tough individuals. However, quantitative research was required to examine these assertions (e.g., Gould et al., 2002). We found partial support for these studies as mental toughness was significantly correlated with coping and optimism and pessimism. More specifically, higher levels of mental toughness were associated with more problem and approach coping behavior and less with avoidance coping.

\section{References}

Bull, S. J., Shambrook, C. J., James, W., \& Brooks, J. E. (2005). Towards an understanding of mental toughness in elite English cricketers. Journal of Applied Sport Psychology, 17, 209-227.

Carver, C. S., Blaney, P. H., \& Scheier, M. F. (1979). Reassertion and giving up: The interactive role of self-directed attention and outcome expectancy. Journal of Personality and Social Psychology, 37, 1859-1870.

Caspi, A., Sugden, K., Moffit, T. E., Taylor, A., Craig, I. W., Harrington, H., et al. (2003). Influences of life stress on depression. Moderation by polymorphic in the 5HTT gene. Science, 301, 386-389.

Chang, C. E., D’Zurilla, T. J., \& Maydeu-Olivares, A. (1994). Assessing the dimensionality of optimism and pessimism using a multi-measure approach. Cognitive Therapy and Research, 18, 143-160. 
Chang, C. E., Maydeu-Olivares, A., \& D'Zurilla, T. J. (1997). Optimism and pessimism as partially independent constructs: Relations to positive and negative affectivity and psychological well-being. Personality and Individual Differences, 23, 433-440.

Clough, P., Earle, K., \& Sewell, D. (2002). Mental toughness: The concept and its measurement. In I. Cockerill (Ed.), Solutions in sport psychology (pp. 32-45). London: Thomson.

Crust, L., \& Clough, P. J. (2005). Relationship between mental toughness and physical endurance. Perceptual and Motor Skills, 100, 192-194.

Dienstbier, R. A. (1989). Arousal and physiological toughness: Implications for mental and physical health. Psychological Review, 96, 84-100.

Fourie, S., \& Potgieter, J. R. (2001). The nature of mental toughness in sport. South African Journal for Research in Sport, Physical Education and Recreation, 23, 63-72.

Gaudreau, P., \& Blondin, J. P. (2002). Development of a questionnaire for the assessment of coping strategies employed by athletes in competitive sport settings. Psychology of Sport and Exercise, 3, 1-34.

Gaudreau, P., \& Blondin, J. P. (2004). Differential associations of dispositional optimism and pessimism with coping, goal attainment, and emotional adjustment during sport competition. International Journal of Stress Management, 11, 245-269.

Gaudreau, P., El Ali, M., \& Marivain, T. (2005). Factor structure of the coping inventory for competitive sport with a sample of participants at the 2001 New York marathon. Psychology of Sport and Exercise, 6, 271-288.

Golby, J., \& Sheard, M. (2004). Mental toughness and hardiness at different levels of rugby league. Personality and Individual Differences, 37, 933-942.

Golby, J., \& Sheard, M. (2006). The relationship between genotype and positive psychological developments in national-level swimmers. European Psychologist, 11, 143-148.

Gould, D., Dieffenbach, K., \& Moffett, A. (2002). Psychological characteristics and their development in Olympic champions. Journal of Applied Sport Psychology, 14, 172-204.

Jones, G., Hanton, S., \& Connaughton, D. (2002). What is this thing called mental toughness? An investigation of elite performers. Journal of Applied Sport Psychology, 14, 205-218.

Jones, G., Hanton, S., \& Connaughton, D. (2007). A framework of mental toughness in the world's best performers. The Sport Psychologist, 21, 243-264.

Khoshaba, D. M., \& Maddi, S. R. (1999). Early experience in hardiness development. Consulting Psychology Journal: Practice and Research, 51, 106-116.

Kobasa, S. C. (1979). Stressful life events, personality, and health: An inquiry into hardiness. Journal of Personality and Social Psychology, 37, 1-11.

Lazarus, R. S. (1999). Stress and emotion: A new synthesis. NY: Springer.

Lazarus, R. S., \& Folkman, S. (1984). Stress, appraisal and coping. NY: Springer.

Levy, A., Polman, R., Clough, P., Marchant, D., \& Earle, K. (2006). Mental toughness as a determinant of sport injury beliefs, pain and rehabilitation adherence. Journal of Sports Rehabilitation, 15, 246-254.

Loehr, J. E. (1986). Mental toughness training for sports: Achieving athletic excellence. Lexington, MA: Lexington.

Middleton, S. C., Marsh, H. W., Martin, A. J., Richards, G. E., Savis, J., Perry, C., Jr., \& Brown, R. (2004). The psychological performance inventory: Is the mental toughness test tough enough? International Journal of Sport Psychology, 35, 91-108.

Mischel, W., \& Shoda, Y. (1995). A cognitive-affective system theory of personality: Reconceptualizing situations, dispositions, dynamics, and invariance in personality structure. Psychological Review, 102, 246-268.

Nicholls, A. R. (2007). A longitudinal phenomenological analysis of coping effectiveness among Scottish international adolescent golfers. European Journal of Sport Science, 7, 169-178.

Nicholls, A. R., Holt, N. L., Polman, R. J. C., \& Bloomfield, J. (2006). Stressors, coping, and coping effectiveness among professional Rugby union players. The Sport Psychologist, 20, 314-329.

Nicholls, A. R., Holt, N. L., Polman, R. J. C., \& James, D. W. G. (2005). Stress and coping among international adolescent golfers. Journal of Applied Sport Psychology, 17, 333-340.

Nicholls, A. R., \& Polman, R. C. J. (2007). Coping in sport: A systematic review. Journal of Sport Sciences, $25,11-31$.

Nicholls, A. R., \& Polman, R. C. J. (in press).Think aloud: Acute stress and coping strategies during golf performances. Anxiety, Stress, \& Coping. 
Norlander, T., \& Archer, T. (2002). Predicting performance in ski and swim championships: Effectiveness of mood, perceived exertion, and dispositional optimism. Perceptual and Motor Skills, 94, 153-164.

Scheier, M. F., \& Carver, C. S. (1985). Optimism, coping, and health: Assessment and implications of generalized outcome expectancies. Health Psychology, 4, 219-247.

Seligman, M. (1990). Learned optimism. NY: Knopf.

Seligman, M. E. P. (1998). Learned optimism: How to change your mind and your life. NY: Pocket Books.

Sheard, M., \& Golby, J. (2006). Effect of psychological skills training programme on swimming performance and positive psychological development. International Journal of Sport and Exercise Psychology, 4, 149-169.

Smith, R. E. (2006). Understanding sport behaviour: A cognitive-affective processing system. Journal of Applied Sport Psychology, 18, 1-27.

Solberg Nes, L., \& Segerstrom, S. C. (2006). Dispositional optimism and coping: A meta-analytical review. Personality and Social Psychology Review, 10, 235-251.

Solberg Nes, L., Segerstrom, S. C., \& Sephton, S. E. (2005). Engagement and arousal: Optimism's effects during a brief stressor. Personality and Social Psychology Bulletin, 31, 111-120.

Thellwell, R., Weston, N., \& Greenlees, I. (2005). Defining and understanding mental toughness in soccer. Journal of Applied Sport Psychology, 17, 326-332.

Venne, S. A., Laguna, P., Walk, S., \& Ravizza, K. (2006). Optimism levels among collegiate athletes and non-athletes. International Journal of Sport and Exercise Psychology, 4, 182-195. 